\title{
Whose Actions are Interactions? From Interface to In-Your-Face
}

\author{
Moderator: Leigh Snelling
}

URCOT

Level 1, 171 La Trobe Street

Melbourne,

Australia, 3000.

zleigh@minyos.its.rmit.edu.au

\section{Panellists \\ Lucy Suchman}

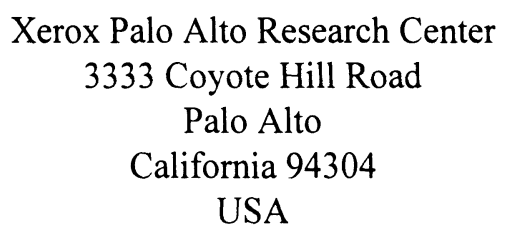

suchman@parc.xerox.com

\section{Joan Greenbaum}

City University of New York

La Guardia College

31-10 Thompson Ave

Long Island City

New York 11101

joanbaum@ix.netcom.com
Toni Robertson

\author{
University of Technology, Sydney \\ PO Box 123 Broadway \\ Sydney \\ New South Wales \\ Australia 2021 \\ T.Robertson@unsw.edu.au \\ Patsy Segall \\ URCOT \\ Level 1, $171 \mathrm{La}$ Trobe Street \\ Melbourne, \\ Australia, 3000. \\ zpatsy@minyos.its.rmit.edu.au
}

\begin{abstract}
The concept of Human Computer Interaction has been a useful one for getting designers and companies to focus on people sitting in front of computers. Much has happened however, in the almost 15 years since $\mathrm{HCI}$ concepts have taken root, and chief among these changes is the importance of the rich picture of how people use computers in their work and daily lives. The panellists will provide critical perspectives on HCl's foundational notions of action and interaction, and constructive proposals for new directions.
\end{abstract}

Human-Computer Interaction: INTERACT'97 S. Howard, J. Hammond \& G. Lindgaard (editors)

Published by Chapman \& Hall OIFIP 1997 
KEYWORDS CSCW, $\mathrm{HCI}$ in organisations, participatory design, situated action, social and political issues

\section{TOPIC OVERVIEW}

This panel proposes that a critical challenge for workers in the field of $\mathrm{HCI}$ is to recognise already existing worlds of interaction at work and daily life and to engage with them in respectful and appropriate ways. To this end, the essential interface when designing computer applications is that between the user and their situation of use, not between an individual user and a computer. We share a concern that the concept of 'interface' has been progressively narrowed to the point where it now represents a set of concerns far removed from the reality of the workplace, the university and the home. Allied to these concerns is a recognition that most human activities are social. The contributions of the panellists are based in traditions that have recognised the sociality of work and the involvement of users in the design of their work and its technologies. These traditions have formed various and changing kinds of relations with $\mathrm{HCI}$ over time and include Participatory Design, situated cognition and action, and the efforts to understand and design for the sociality of work that have been defining of Computer Supported Cooperative Work (CSCW).

Participatory Design, an approach to the design of technology that is firmly tied to wider traditions of workplace democracy, has influenced the development of $\mathrm{HCI}$ by insisting that its focus on the design of the human computer interface includes the meaningful inclusion of workers at every stage in the design process. Both situated cognition and action emphasise the role of interaction and context in organising behaviour. It recognises the limitations of the symbol processing metaphor for cognition and insists, instead, on an understanding of human cognition as situated, embodied action that always occurs within a context of particular, concrete circumstances.

Finally, Computer Supported Cooperative Work (CSCW) represents a welcomed wider scope to the original $\mathrm{HCI}$ focus by expanding the focus of study to include the support of people working together. This shift has highlighted the collaborative and social nature of all work. As a result, insights from research disciplines devoted to understanding human action and social organisation, have been applied to the design of computer systems that aim to effectively support human interaction.

Viewed from each of these perspectives, the notion of human-computer interaction is problematic, as it implies that what happens when people use computers equates, in some way, with interactions between people. The equation of human-human and human-computer interactions has contributed to the development of discourses and practices that assume the computer to be some kind of surrogate other. The result is the attribution of interactional agency to computers, when their role is more appropriately conceptualised as mediating the interaction between people and their work, other people, their collective work and the environment within which that work is performed.

The concept of Human Computer Interaction has been a useful one for getting designers and companies to focus on people sitting in front of computers. Much has happened however, in the almost 15 years since $\mathrm{HCI}$ concepts have taken root, and chief among these changes is the importance of the rich picture of how people use computers in their work and daily lives

The panellists will argue, in various ways, that $\mathrm{HCI}$ needs to contribute to an understanding of computers as artefacts that mediate human action and interaction within specific contexts of use. Further, the panellists do not assume that work places are not comprised of groups of people with equal roles, responsibilities and power, but are constructed of layers of bureaucracy, of fine distinctions between decision makers and operators, and between those representing the interests of capital and those representing the interests of labor.

In sum, the panel will provide both critical perspectives on $\mathrm{HCl}$ 's foundational notions of action and interaction as well as constructive proposals for new, politically and historically aware research and development directions. 


\section{PANELLISTS' PERSPECTIVES}

\section{Lucy Suchman}

In his contribution to the volume Design at Work (1991), Liam Bannon proposed a shift for HCI 'from human factors to human actors.' In this concise phrase, Bannon points us away from a narrow construal of the user as a necessary element of interface design, to a view of system design as a multifaceted enterprise in support of persons engaged in ongoing activity.

In the years since Bannon's proposal, research in $\mathrm{HCI}$ has made significant moves out of the laboratory and into the workplace. Yet, for the most part, technologies continue to be evaluated with reference to feature sets and comparable offerings, rather than in terms of their fit with the environments and activities of their use. In my panel comments I'll sketch a vision of an alternative future for $\mathrm{HCI}$ in which design awards are given not for discrete, decontextualised devices but for the collective achievement of new, more productive connections among artifacts, and more powerful integrations between artifacts and the settings of their use.

\section{Joan Greenbaum}

I will bring the Participatory Design perspective to the debate. Participatory design has strong local traditions in Australia, Germany, Scandinavia and the U.S. where it has represented both a better way to design systems that fit use situations and a movement to gain more workplace rights through participation in technological decision-making. Joan Greenbaum has worked in the computer field for the last 30 years actively focusing on getting users involved in all stages of design. In this panel she will present the need for integrating $\mathrm{HCI}$ techniques such as usability labs with more active participation of users in design. In addition she argues that realistic design alternatives need to include labor issues as well as the direct participation of workers, customers and citizens in order to reframe design agendas. In-your-face design is more than just a pretty interface.

\section{Toni Robertson}

Because people are always situated in social contexts, all work can be considered as cooperative. What varies are the degree of reliance on other people at different stages in the work processes and the degree of control any individual has over both the definition of a particular process as well as the organisation of their own and others' contribution to that process. Negotiating and achieving cooperative work then, is itself part of that work and its success is determined by the skills and commitment of those involved. When work is mediated by the use of technology, the successful use of that technology is determined as much by the skills of the users in meshing the technology into the work process, as it is by any specific qualities of the technology itself. These skills are excluded from consideration when the concerns of technology designers are limited to whether users are novices or experts in the use of a particular software application.

$\mathrm{HCI}$ has traditionally relied on the cognitivist metaphor for human cognition that sets up an opposition between 'inside the head' and 'outside the head'. Cognition is reduced to input and output from an information processing brain. Based on empirical studies of cooperative design I will consider the inadequacies of the cognitivist metaphor, and related oppositions, to account for human cognition as it is lived and for cooperative work as it is achieved in practice.

The basic problem is that cognitivism ignores that human cognition is embodied cognition that is continually defined by, and defining of, both interaction and context. The result is that communicative work involved in achieving a cooperative process as well as the skills required to do this work remain unacknowledged and frequently unsupported in the design of technology that might be used in cooperative work. 


\section{Patsy Segall}

Traditional, formal methods of systems development clearly identified the points at which 'user' input formed part of the development process. Typically, critical points identified in the waterfall model were in the requirements gathering phase and, much further down the track, the interface design phase. Testing an interface after the functional specification phase will ensure only that it is 'usable', not that it is 'really useful'. Contrasting approaches which attempt to solve this problem involve intensive joint participation of users and developers. For example, Tom Dayton has described the approach he and others developed at Bellcore as a 'whitewater' approach which encourages very rapid iteration of analysis, design and testing.

These kinds of approaches acknowledge that what is accessed (and how) on a screen is not readily separable from deep functionality. However they do not explicitly address the issue raised by Grudin: the terms 'user' and 'user interface', obscure the complexity and variability of the work different 'users' undertake and the environment within the work is carried out. Further, the screen and how it is manipulated is a product of the technical infrastructure which supports the presentation layer. In large organisations, this infrastructure consists of mixed resources laid down at different times for different purposes. Landscape gardening has been proposed by Mike Hales and others as a metaphor which may be a helpful way to conceptualize the tasks and processes needed to achieve durable improvements in work practices and the systems supporting the work, and I would like to explore this further. 